\title{
Learning curve of laparoscopic hysterectomy and comparison with abdominal hysterectomy
}

\author{
Patil P. ${ }^{1}$, Sharma P. ${ }^{2}$, Banga Siftie-Kaur ${ }^{3}$ \\ ${ }^{1}$ Dr. Pooja Patil, Professor, ${ }^{2}$ Dr. Priyanka Sharma, Consultant, Sitadevi Hospital, Jaipur (RJ), ${ }^{3}$ Dr. Siftie-Kaur Banga, PG \\ First Year Resident, Department of Obstetrics and Gynaecology, LN Medical College and JK Hospital and Medical \\ Research Centre, Bhopal (MP)
}

Correspondence Author: Dr. Siftie-Kaur Banga, PG First Year Resident, Department of Obstetrics and Gynaecology, LN Medical College and JK Hospital and Medical Research Centre, Bhopal (MP) India. E-mail: sifb13@gmail.com

\begin{abstract}
Introduction: Laparoscopic hysterectomy is the most emerging route with major drawback of long learning curve and longer initial time taken for surgery. Objectives: 1) To compare two different routes of hysterectomy: abdominal and laparoscopic in terms of surgical outcomes and complications. 2) To see the learning curve of laparoscopic hysterectomy. Material and Methods: 100 patients admitted for hysterectomy were divided into two groups of 50 each, first group planned for abdominal hysterectomy and second group planned for laparoscopic route. Data was collected regarding amount of blood loss, duration of surgery, post operative requirement of analgesics, duration of hospital stay, and post operative complications in both groups. Results: The main indications for hysterectomy were fibroid, AUB, adenomyosis, endometrial hyperplasia and polyp in both groups. The average blood loss in TAH group ( $\mathrm{n}=50)$ was 285 $\mathrm{ml}$ and in TLH group $(\mathrm{n}=50)$ was $246 \mathrm{ml}(\mathrm{p}=0.0588)$. Average blood loss in first 25 cases of TLH was $348 \mathrm{ml}$ and in next 25 cases was $144 \mathrm{ml}$, which was highly significant. The average time taken in TAH group was 95 minutes, and in TLH group was 141 minutes ( $\mathrm{p}=1.415 \mathrm{E}-13$ ) which was highly significant. In TLH group, the average time taken in first 25 cases was 166 minutes and in next 25 cases it was 116 minutes which is significant. Requirement of analgesics and duration of stay was less in TLH group. Minor complications like fever, UTI were comparable in both groups. Conclusion: Learning curve of laparoscopic hysterectomy can be reduced with good team work, a proper selection of patients, and the use of good instruments.
\end{abstract}

Key words: Laparoscopic hysterectomy, UTI

\section{Introduction}

Laparoscopic hysterectomy is the most emerging route of hysterectomy in present day scenario due to the advantages of minimally invasive surgery. Hysterectomy is one of the most common surgical procedures performed in gynaecology [1-3]. The most common benign indications for hysterectomy are fibroid uterus, DUB, polyp, endometrial hyperplasia, genital prolapse, and adenomyosis $[4,5]$.

The advantages of laparoscopic hysterectomy are shorter hospital stay, a smaller wound, less blood loss, less post operative pain, early ambulation of the patient and early and more rapid recovery of the patient [4,5]. Another major advantage is that laparoscopy offers

Manuscript received: $10^{\text {th }}$ June 2019

Reviewed: $20^{\text {th }}$ June 2019

Author Corrected: $26^{\text {th }}$ June 2019

Accepted for Publication: $30^{\text {th }}$ June 2019 visualization and magnification which in turn enables proper access to the underlying structures [6]. The disadvantages include a learning curve leading to a longer operating time, expertise and experience required and higher costs [4,5]. More and more surgeons, as well as patients are preferring to opt for minimally invasive surgical protocols.

Indeed, with a proper selection of patients, laparoscopic hysterectomy has shown to be a safe method that offers all the advantages mentioned [7]. However, a steep learning curve associated with laparoscopy plays a major role when deciding which surgical route to opt for. In our institute predominantly abdominal route and vaginal route were preferred for hysterectomy, thus this study was designed to relate the complications and outcome due to the laparoscopic mode of hysterectomy. 


\section{Objectives}

The purpose of this prospective study was twofold. Firstly, to compare two different routes of hysterectomy: abdominal and laparoscopic in terms of surgical outcomes and complications. Secondly, to assess the learning curve of laparoscopic hysterectomy by comparing between first 25 cases and next 25 cases in regard to the total time taken to perform the surgery and the amount of blood loss during surgery.

\section{Material and Methods}

Setting: JK Hospital and Medical Research Centre, Bhopal, Madhya Pradesh

Duration of study: 2 years (2016-2018)

Sampling methods: Hundred patients admitted in the gynaecology ward of JK Hospital requiring hysterictomy with a uterus size less than 14 weeks were counselled for surgery via the laparoscopic route and its advantages. Those who agreed for laparoscopic guided surgery were operated through this route (group TLH), whereas those who disagreed were operated through the abdominal route (group TAH).50 patients were assigned to each group.

Inclusion criteria: Patients with a uterus less than 14 weeks size with benign uterine lesions.

Exclusion criteria: Patients with a uterus larger than 14 weeks size and all known cases of genital carcinomas.
Statistical methods: All obtained data was recorded in numbers and percentage. Pooled variance, student t test, and $\mathrm{p}$ value were calculated to find the significance of the results.

Ethical consideration and permission: This study was approved by the Institutional Ethical Committee. Surgical procedure: In laparoscopic hysterectomy, the main port was placed two finger breadths above the umbilicus. Three accessory ports, two on the left side and one on the right side, were made. Manipulation was done with the use of a vaginal manipulator. Basic steps of laparoscopic hysterectomy were done using bipolar as the energy source and the instrument used was dissector. Vault was opened by a monopolar hook. Abdominal hysterectomy was done in routine manner.

Methodology: Detailed history of the patient was taken and complete routine investigations were done. Once fitness was obtained, patients were taken for surgery. Both groups were compared in terms of amount of blood loss during surgery ( $\mathrm{ml}$ ), duration of surgery (minutes), post operative requirement of analgesics (Diclofenac given 8 hourly), duration of hospital stay (days), and post operative complications. In laparoscopic group, comparison was done between the first 25 cases and next 25 cases in terms of duration of surgery and amount of blood loss during surgery, in order to see the learning curve of laparoscopic hysterectomy.

\section{Results}

When analyzing the socio-demographic data of patients in both groups, it was observed that the mean age in both groups was quite similar and there was no statistical significance. The mean age in TAH group was 45.24 and in TLH group it was 43.84 .

Table 1: Age-wise distribution of patients

Table-1: Shows the age-wise distribution of patients in both the groups.

\begin{tabular}{|c|c|c|c|c|}
\hline \multirow{2}{*}{ Age } & \multicolumn{2}{|c|}{ Abdominal hysterectomy } & \multicolumn{2}{c|}{ Laparoscopic hysterectomy } \\
\cline { 2 - 5 } & $\mathbf{n}$ & $\mathbf{\%}$ & $\mathbf{n}$ & $\mathbf{\%}$ \\
\hline $30-40$ years & 8 & 16 & 10 & 20 \\
\hline $41-50$ years & 37 & 74 & 33 & 66 \\
\hline $51-60$ years & 5 & 10 & 7 & 14 \\
\hline
\end{tabular}

Parity wise distribution of patients is as shown in Table 2. Majority of the patients were multiparous in both the groups.

Table-2: Parity-wise distribution of patients.

\begin{tabular}{|l|c|c|c|c|}
\hline \multirow{2}{*}{ Parity } & \multicolumn{2}{|c|}{ Abdominal hysterectomy } & \multicolumn{2}{c|}{ Laparoscopic hysterectomy } \\
\cline { 2 - 5 } & $\mathbf{n}$ & $\mathbf{\%}$ & $\mathbf{n}$ & $\mathbf{\%}$ \\
\hline Nulliparous & 1 & 2 & 0 & - \\
\hline Multipara (1-4) & 32 & 64 & 29 & 58 \\
\hline
\end{tabular}


Original Research Article

\begin{tabular}{|l|l|l|l|l|}
\hline Grand multipara (>4) & 17 & 34 & 21 & 42 \\
\hline
\end{tabular}

Indications for surgery were similar in both the groups with the major indications being fibroid uterus and DUB, as shown in Table 3. Other indications included adenomyosis, endometrial hyperplasia and polyp.

Table 3: Indication-wise distribution of patients

\begin{tabular}{|c|c|c|c|c|}
\hline \multirow{2}{*}{ Indication } & \multicolumn{2}{|c|}{ Abdominal hysterectomy } & \multicolumn{2}{c|}{ Laparoscopic hysterectomy } \\
\cline { 2 - 5 } & $\mathbf{n}$ & $\mathbf{\%}$ & $\mathbf{n}$ & 18 \\
\hline Fibroid & 17 & 34 & 9 & 32 \\
\hline DUB & 13 & 26 & 16 & 24 \\
\hline Adenomyosis & 7 & 14 & 12 & 8 \\
\hline Endometrial hyperplasia & 5 & 10 & 4 & 18 \\
\hline
\end{tabular}

Mean duration of surgery in minutes varied between the two groups as shown in Table 4. The mean duration in TAH group was 95 minutes, whereas in TLH group it was 141 minutes $(\mathrm{p}=1.41 \mathrm{E}-13)$. Statistical analysis showed that the obtained results were highly significant. Moreover, comparison was done between the first 25 laparoscopic cases operated in which the mean duration of surgery was 166 minutes and the next 25 cases in which the mean duration was 116 minutes. Unpaired $\mathrm{T}$ test was applied and results were found to be highly significant. The decrease in time taken shows the learning curve of this mode of hysterectomy.

Table-4: Mean duration of surgery.

\begin{tabular}{|c|c|c|c|c|c|}
\hline & $\begin{array}{c}\text { Abdominal } \\
\text { hysterectomy }\end{array}$ & $\begin{array}{c}\text { Laparoscopic } \\
\text { hysterectomy }\end{array}$ & pooled variance & t test & p value \\
\hline $\begin{array}{c}\text { Mean duration of } \\
\text { surgery (minutes) }\end{array}$ & 95 & 141 & 741.837 & -8.444 & $1.415 \mathrm{E}-13$ \\
\hline
\end{tabular}

Next, the amount of blood loss during surgery was observed and analyzed statistically as shown in Table 5. There was a blood loss of $285 \mathrm{ml}$ in the TAH group, whereas in the TLH group the blood loss was of $246 \mathrm{ml}$. Although similar, these results were statistically insignificant $(\mathrm{p}=0.0588)$. However, when comparison was made between the first 25 laparoscopic cases and the next 25 cases, results were highly significant. In the first 25 cases, the average amount of blood loss was $328 \mathrm{ml}$, whereas in the next 25 cases it was $144 \mathrm{ml}$. The improvement and better control of blood loss shows the learning curve of laparoscopic hysterectomy.

Table-5: Blood loss during surgery.

\begin{tabular}{|c|c|c|c|c|c|}
\hline & $\begin{array}{c}\text { Abdominal } \\
\text { hysterectomy }\end{array}$ & $\begin{array}{c}\text { Laparoscopic } \\
\text { hysterectomy }\end{array}$ & pooled variance & t test & p value \\
\hline $\begin{array}{c}\text { Average blood } \\
\text { loss (ml) }\end{array}$ & 285 & 246 & 15259.694 & 1.578 & 0.0588 \\
\hline
\end{tabular}

The average dose of analgesia required post-operatively was also analyzed as shown in Table 6 . The TAH group required a higher amount of analgesia, 13.2 doses as compared to 5.38 doses required in the TLH group. This was found to be statistically highly significant $(\mathrm{p}=1.859 \mathrm{E}-28)$.

Table-6: Average analgesia dose required post-operatively

\begin{tabular}{|c|c|c|c|c|c|}
\hline & $\begin{array}{c}\text { Abdominal } \\
\text { hysterectomy }\end{array}$ & $\begin{array}{c}\text { Laparoscopic } \\
\text { hysterectomy }\end{array}$ & $\begin{array}{c}\text { pooled } \\
\text { variance }\end{array}$ & $\mathrm{t}$ test & $\mathrm{p}$ value \\
\hline $\begin{array}{c}\text { Average analgesia } \\
\text { dose required }\end{array}$ & 13.2 & 5.38 & 6.345 & 15.523 & $1.859 \mathrm{E}-28$ \\
\hline
\end{tabular}




\section{Original Research Article}

Similarly, the average number of days stayed in the hospital post-operatively was also greater in the TAH group. Duration of stay was 8.2 days in the TAH group, whereas it was 4.5 days in the TLH group, as shown in Table 7 .

Table-7: Average number of days stayed in hospital post operatively

\begin{tabular}{|c|c|c|}
\hline & Abdominal hysterectomy & Laparoscopic hysterectomy \\
\hline Average number of days in hospital & 8.2 & 4.5 \\
\hline
\end{tabular}

Complications were more commonly seen in the TAH group, as shown in Table 8. One ureteric injury occurred, in the TAH group, at the vault angle due to inadvertent bleeding at the vault, which was diagnosed post-operatively. Two bladder injuries occurred in the TAH group, in which both the patients had a history of two previous cesarean sections and due to which the bladder was densely adherent. Three patients in the TAH group had wound dehiscence. All of these complications were absent in the TLH group. In the TLH group, only complications occurring post-operatively were vault bleeding and urinary tract infection.

Table-8: Complication-wise distribution of patients.

\begin{tabular}{|c|c|c|}
\hline Complications & Abdominal hysterectomy & Laparoscopic hysterectomy \\
\hline Fever & 8 & 0 \\
\hline UTI & 9 & 4 \\
\hline Bladder injury & 2 & 0 \\
\hline Ureteric injury & 1 & 0 \\
\hline Intestinal injury & 0 & 5 \\
\hline Vault bleeding & 11 & 0 \\
\hline Vault hematoma & 2 & 0 \\
\hline Wound dehiscence & 3 & 0 \\
\hline
\end{tabular}

\section{Discussion}

The socio-demographic data shows that most commonly women of pre-menopausal age group require hysterectomy. Kanmani, M. et al conducted a comparative study that showed that there was no significant difference between the two groups in terms of the mean age of patients. In the TAH group, mean age was $46.5 \pm 8.9$, whereas in the TLH group it was $46.9 \pm 6.9$ (p-08) [4]. Similarly, in this study the mean age in the abdominal group was 45.24 years and in the laparoscopic group it was 43.84 years.

A study conducted by Kanmani, M. et al showed that the most common indications for hysterectomy, regardless of the route chosen, in order of frequency were majorly fibroid followed by adenomyosis, endometriosis, ovarian cyst and DUB [4].

Another study by Nanavati, A. et al showed that the most common indication in both abdominal and laparoscopic group was DUB $(54 \%$ in TAH group and $44 \%$ in $\mathrm{TLH}$ group). Other indications were fibroid uterus and adenomyosis [5]. In this study, the most common indications for surgery were similar in both the groups with the major indications being fibroid uterus and DUB. Other indications included adenomyosis, endometrial hyperplasia and polyp.

Balci O. conducted a study in which the mean time of operation was longer in case of laparoscopic hysterectomy as compared to abdominal hysterectomy $(105.4 \pm 22.9$ minutes vs.74 $\pm 18, \mathrm{p}<0.001)$ [7]. The results obtained in this study also showed that the mean duration of surgery varied according to the route. The mean duration in abdominal route was 95 minutes, whereas in laparoscopic route it was 141 minutes $(\mathrm{p}=$ $1.41 \mathrm{E}-13)$.

Another study conducted by Kim SM. et al. compared the surgical outcomes between single-port access laparoscopic hysterectomy (SPA-TLH), multi-port access laparoscopic hysterectomy (MPA-TLH) and total abdominal hysterectomy (TAH). The duration of surgery was longest in SPA-TLH (188 \pm 51.3 minutes), followed by the TAH (176.4 \pm 47.9 minutes) and MPATLH $(149.3 \pm 59.5$ minutes $)$ groups $(\mathrm{p}<0.05)$ [8]. Garry R. et al. conducted a multicentre randomized trial comparing abdominal, vaginal and laparoscopic methods of hysterectomy. The study showed that the laparoscopic hysterectomy procedure took 84 minutes 


\section{Original Research Article}

as compared with 72 minutes for the abdominal hysterectomy procedure [9]. All the above results infer that the difference seen in duration of surgery may differ with the expertise of each individual surgeon.

Terzi H. et al. conducted a study to assess the learning curve of laparoscopic hysterectomy and came to the conclusion that there is indeed a learning curve to this operation which is confirmed by the decrease in operating time correlated to the gain in experience. The average duration of surgery reduced significantly from 76.2 minutes to 68.9 minutes $(p=0.001)$ between the first and second 75-patients groups [6].

In this study, comparison of average duration required was also done between the first 25 cases and the next 25 cases of TLH group in order to assess the learning curve of laparoscopic hysterectomy. The mean duration of surgery in first 25 TLH cases was 166 minutes and in the next 25 cases it was 116 minutes. Unpaired T test was applied and results were found to be highly significant. Perino A. et al. undertook a randomized study to compare the short-term results between total laparoscopic hysterectomy and abdominal hysterectomy.

The average operative time was $104.1 \pm 26.98$ minutes for laparoscopic hysterectomy, and according to the learning curve the range was between 72-163 minutes [10]. This indicates that as the expertise of the surgeon increases with time, the average time required performing the surgery, and with that the complications associated with anaesthesia, both decrease.

The study by Kim SM. et al. showed that the amount of blood loss was greatest in the TAH group (427.1 \pm 250.6 $\mathrm{ml}, \mathrm{p}<0.05)$ as compared to the MPA-TLH and SPATLH groups (163.8 \pm 168.9 and $176.9 \pm 197.8 \mathrm{ml})$ [8]. Perino, A. et al. also gave results that showed that the average blood loss during surgery was lower in laparoscopic hysterectomy than in abdominal ( $\mathrm{p} \leq$ 0.001) [10]. Same results were found in this study, in which the average amount of blood loss during surgery in the abdominal group was $285 \mathrm{ml}$, whereas in the laparoscopic group it was $246 \mathrm{ml}(\mathrm{p}=0.0588)$.

Moreover, the average amount of blood loss in first 25 laparoscopic cases was $328 \mathrm{ml}$, whereas in the next 25 cases it was $144 \mathrm{ml}$. The improvement and better control of blood loss shows the learning curve of laparoscopic hysterectomy.As the skill improves, the amount of blood loss intra-operatively reduces significantly.
A study conducted by Sutasanasuang, S. showed that there was less postoperative pain in the laparoscopic procedure as shown by the required doses of analgesics. In the TLH group, dosage of meperidine was $95.4 \pm 43.2$ $\mathrm{mg}$, whereas in the TAH group, it was $2368 \pm 20.7 \mathrm{mg}$. [11]. This study also confirmed that the average dose of analgesia required post-operatively was greater in the abdominal group. The TAH group required 13.2 doses of diclofenac as compared to 5.38 doses required in the TLH group $(\mathrm{p}=1.859 \mathrm{E}-28)$. Lesser post operative pain indicates a better surgical outcome in terms of earlier mobilization, earlier return to routine activities and therefore a better quality of life.

Balci O. showed in their study that the mean duration of hospital stay was less in the laparoscopic group due to earlier mobilization $(2.48 \pm 0.6$ days vs. $4.88 \pm 1.2$, $\mathrm{p}<0.001$ ) [7].In the study by Kim SM. et al., the duration of stay in the hospital post-operatively was longest in the TAH group $(7.0 \pm 2.1$ days $)$, followed by SPA-TLH (6.3 \pm 2.0$)$ and MPA-TLH (5.5 \pm 2.0$)$ groups [8].The results of this study also showed that the average number of days stayed in the hospital postoperatively was more in the TAH group.

Patients in the TAH group stayed on average 8.2 days, whereas in the TLH group it was 4.5 days. Garry R. et al. conducted a multicentre randomized trial and study results showed that compared with abdominal hysterectomy, laparoscopic hysterectomy was associated with shorter hospital stay. The study showed that patients undergoing abdominal hysterectomy generally stayed approximately one day longer than patients undergoing laparoscopic hysterectomy (5 days compared to 4 days).

In fact, laparoscopic hysterectomy was found to be associated with a significantly better quality of life postoperatively [9]. Study by Perino, A. et al. showed that the average duration of hospital stay was $2.38 \pm 0.30$ days in the TLH group, whereas it was $6.23 \pm 1.85$ days in the TAH group. These results are also similar to the ones obtained in this study, which indicates the benefits of laparoscopic routes intra-operatively as well as postoperatively [10]. The study conducted by Kim SM. et al. compared the complications arising between these two routes of hysterectomy. The major complication rate was $2.5 \%$ in the TAH group, $5.5 \%$ in the MPATLH group, and $0.7 \%$ in the SPA-TLH group[8]. Terzi $H$. et al. conducted a study that showed a reduction in the rate of all complications from $8 \%$ in the first group of 75 patients, to $6.7 \%$ in the second group, and $4.7 \%$ in the final group. However, this decline was not 


\section{Original Research Article}

significant statistically $(\mathrm{p}=0.6)$ [6]. Similarly, in this study, complications were more commonly seen in the total abdominal hysterectomy group, as compared to the laparoscopic hysterectomy group.

Yi YX. et al. conducted a meta-analysis of twenty-three trials to assess whether laparoscopic-assisted vaginal hysterectomy achieves better clinical results compared with abdominal hysterectomy for benign diseases. The study results showed that although laparoscopic-assisted vaginal had a longer operation time, its advantages were that it had less blood loss, shorter post-operative duration of hospital stay, less postoperative pain, and therefore earlier and quicker return to routine activities[12].

Kluivers KB. et al. conducted a comparative study to assess the difference in quality of life and surgical outcome after total laparoscopic hysterectomy as compared to abdominal hysterectomy.

Their study came to the conclusion that laparoscopic route results in more postoperative vitality, therefore a better quality of life, when compared with abdominal route. Therefore, they suggest that all women with a benign condition requiring hysterectomy should be counseled properly and given the choice to choose the laparoscopic method [13].

\section{Conclusion}

Even though laparoscopic hysterectomy is an emerging mode of hysterectomy and holds many advantages, it has a learning curve to it therefore requires patience. It is commonly seen that there is an initial apprehension in performing laparoscopic hysterectomy as it requires skill and expertise. However, the present study shows that these skills can be easily acquired. Indeed, all gynaecologists doing open or abdominal hysterectomies can perform laparoscopic hysterectomy with a proper selection of patients, good team work, following proper ergonomics, and with the use of good instruments and energy source.

\section{What the present study add to existing knowledge?}

When compared with the abdominal route, the laparoscopic route is beneficial for the patient as there is earlier mobilization, lesser post operative pain and minimal scarring. Therefore, this mode of operation should be preferred and taught in all institutes.
Dr. Pooja Patil: Collection of all the data required, preparation of the manuscript.

Dr. Priyanka Sharma: Tabulation of the results, preparation of the manuscript.

Dr. Siftie-Kaur Banga: Concept, study design, preparation of the manuscript.

Funding: Nil, Conflict of interest: Nil

Permission from IRB: Yes

\section{References}

1. Weber AM, Lee JC. Use of alternative techniques of hysterectomy in Ohio, 1988-1994. N Engl J Med. 1996; 335 (7): 483-9. DOI:10. 1056/ NEJM 199608153350 706

2. Marana R, Busacca M, Zupi E, et al. Laparoscopically assisted vaginal hysterectomy versus total abdominal hysterectomy: a prospective, randomized, multicenter study. Am J Obstet Gynecol. 1999; 180(2 Pt 1):270-5. DOI:10.1016/s0002-9378 (99)70199-7

3. McCracken G, Hunter D, Morgan D, Price JH. Comparison of laparoscopic- assisted vaginal hysterectomy, total abdominal hysterectomy and vaginal hysterectomy. Ulster Med J. 2006; 75(1): 54-58.

4. Kanmani, M., Mirudhubashini, G., Vishranthi, S. Comparative study of surgical results between total abdominal hysterectomy and total laparoscopic hysterectomy in a tertiary hospital: a 2 year retrospective study. Int. J Reprod Contracept Obstet Gynecol. 2018;7(3):1019-1023. DOI: http://dx.doi.org/ 10. 18203 /2320-1770.ijrcog20180884.

5. Nanavati AM, Gokral SB. A prospective randomized comparative study of vaginal, abdominal, and laparoscopic hysterectomies. J Obstet Gynecol India. 2016; 66 (1):389-94.DOI: 10.1007/s13224-015-0756-z.

6. Terzi H, Biler A, Demirtas O, Guler OT, Peker N, Kale A Terzi H, Biler A, Demirtas O. Total laparoscopic hysterectomy: Analysis of the surgical learning curve in benign conditions. Int J Surg. 2016;35:51-57. DOI: 10.1016/j.ijsu.2016.09.010.

7. Balcı O. Comparison of total laparoscopic hysterectomy and abdominal hysterectomy.Turk J Obstet Gynecol. 2014;11(4):224-227. DOI:10.4274/ tjod. 47108 .

\section{Author's contribution}




\section{Original Research Article}

8. Kim SM, Park EK, Jeung IC, Kim CJ, Lee YS. Abdominal, multi-port and single-port total laparoscopic hysterectomy: eleven-year trends comparison of surgical outcomes complications of 936 cases. Arch Gynecol Obstet. 2015;291(6):1313-9. DOI: 10.1007/s 00404-014-3576-y.

9. Garry R, Fountain J, Brown J, Manca A, Mason S, Sculpher M, et al. Evaluate hysterectomy trial: a multicentre randomised trial comparing abdominal, vaginal and laparoscopic methods of hysterectomy. Health Technol Assess. 2004;8(26):1-154.DOI:https:// doi.org/10.3310/hta8260

10. Perino A, Cucinella G, Venezia R, Castelli A, Cittadini E. Total laparoscopic hysterectomy versus total abdominal hysterectomy: an assessment of the learning curve in a prospective randomized study. Human Reproduction. 1999;14(12):2996-9.DOI: https:// doi. org/ 10.1093/humrep/14.12.2996
11. Sutasanasuang S. Laparoscopic hysterectomy versus total abdominal hysterectomy: a retrospective comparative study. J Med Assoc Thai. 2011;94(1):8-16. 12. Yi YX, Zhang W, Zhou Q, Guo WR, Su Y. Laparoscopic- assisted vaginal hysterectomy vs abdominal hysterectomy for benign disease: a metaanalysis of randomized controlled trials. Eur J Obstet Gynecol Reprod Biol. 2011;159(1):1-18. DOI: 10.1016 / j. ejogrb.2011.03.033.

13. Kluivers KB, Hendriks JC, Mol BW, Bongers MY, Bremer GL, de Vet HC, et al. Quality of life and surgical outcome after total laparoscopic hysterectomy versus total abdominal hysterectomy for benign disease: a randomized, controlled trial. J Minim Invasive Gynecol. 2007;14(2):145-52. DOI:10.1016/j.jmig.2006. 08.009

\section{How to cite this article?}

Patil P, Sharma P, Banga Siftie-Kaur. Learning curve of laparoscopic hysterectomy and comparison with abdominal hysterectomy.Obs Rev: J obstet Gynecol 2019;5(2):112-118.doi:10.17511/joog.2019.i02.05. 